\title{
Shear-Strengthening of Reinforced \& Prestressed Concrete Beams Using FRP: Part I - Review of Previous Research
}

\author{
Moustapha Ibrahim Ary ${ }^{1)}$ and Thomas H.-K. Kang ${ }^{2), *}$
}

(Received January 4, 2012, Revised February 9, 2012, Accepted February 13, 2012)

\begin{abstract}
Fiber-Reinforced Polymers (FRP) are used to enhance the behavior of structural components in either shear or flexure. The research conducted in this paper was mainly focused on the shear-strengthening of reinforced and prestressed concrete beams using FRP. The main objective of the research was to identify the parameters affecting the shear capacity provided by FRP and evaluate the accuracy of analytical models. A review of prior experimental data showed that the available analytical models used to estimate the added shear capacity of FRP struggle to provide a unified design equation that can predict accurately the shear contribution of externally applied FRP. In this study, the ACI 440.2R- $08^{1}$ model and the model developed by Triantafillou and Antonopoulos ${ }^{2}$ were compared with the prior experimental data. Both analytical models failed to provide a satisfactory prediction of the FRP shear capacity. This study provides insights into potential reasons for the unsatisfactory prediction.
\end{abstract}

Keywords: FRP, prestressed concrete, shear, strengthening, rehabilitation.

\section{Introduction}

Concrete structures deteriorate over time, and therefore implementing a design approach aimed at rehabilitating critical structural members such as beams, columns and bridge girders is necessary. One of the problems encountered in these critical members is their deficiency in sustaining the applied shear load over time. Fiber-Reinforced Polymers (FRP) are composite systems of fibers embedded in a polymeric matrix. ${ }^{3}$ Rehabilitation of Reinforced Concrete (RC) members using FRP was introduced more than two decades ago. ${ }^{4}$ Multiple studies, such as the ones conducted by Khalifa and Nanni, ${ }^{3}$ Bimal and Hiroshi, ${ }^{5}$ and Pellegrino and Modena, ${ }^{6,7}$ have shown that applying FRP to RC beams increases the overall shear capacity of a structural member. Due to the complex nature of shear design even in simple reinforced concrete beams, determining the exact contribution of the Fiber Reinforced Polymers in shear is still under investigation and the results thus far are not really converging toward a generalized prediction model. In order to better understand the behavior of FRP applied externally to an $\mathrm{RC}$ or prestressed concrete member, a literature review was conducted to assess the current state of the art for shear-strengthening of members using fiber-reinforced polymers (FRP), particularly carbon fiber-reinforced polymers (CFRP) which is the most common material used for shear-strengthening.

\footnotetext{
${ }^{1)}$ School of Civil Engineering and Environmental Science, University of Oklahoma, Norman, OK 73019, USA.

${ }^{2)}$ KCI Member, Department of Architecture and Architectural Engineering, Seoul National University, Seoul 151-744, Korea.

*Corresponding Author; E-mail: tkang@snu.ac.kr

Copyright (c) 2012, Korea Concrete Institute. All rights reserved, including the making of copies without the written permission of the copyright proprietors.
}

The literature review was followed by an evaluation of the existing experimental data tested by other researchers and analytical models currently available for estimating the shear capacity provided by the FRP.

\section{Review of research on shear-strengthening using FRP}

In this section, a review is presented regarding various experimental research programs dealing with the shear contribution of FRP, the most common material used for shear-strengthening of concrete beams. This section also assesses the current state of the art concerning FRP used for shear-strengthening concrete beams.

\subsection{Influence of transverse reinforcement and shear span-to-depth ratio on CFRP efficiency}

Khalifa and Nanni ${ }^{3}$ tested twelve full-scale beams, of which eight had no transverse steel reinforcement in the shear span (SO series) and four specimens with transverse reinforcement in the shear span (SW series). All beams were designed to fail in shear. Two shear span-to-depth ratios $\left(a^{\prime} / d=3\right.$ and 4$)$ were used. The specimens were strengthened using continuous U-wraps, wraps bonded on the sides, and strips of U-wrapped CFRP (see Figure 1). All of these strengthening configurations were used with various fiber orientations.

The authors studied the influence of shear span-to-depth ratio and internal steel reinforcement on the shear capacity of externally bonded CFRP sheets. Although specimens with transverse reinforcement showed a lower increase in shear capacity than similar specimens without transverse reinforcement in the shear span, the increase in shear capacity was significantly dependent on the shear span-to-depth ratio $(a / d)$. Khalifa and Nanni ${ }^{3}$ noted an $80 \%$ 


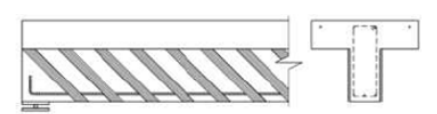
Side bonding

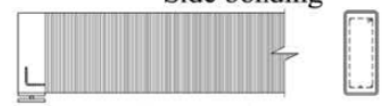

Fully wrapping

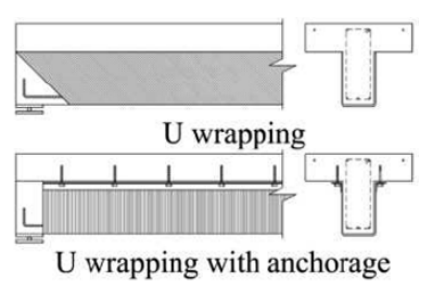

U wrapping with anchorage
Fig. 1 Various FRP configurations (Adapted from Sas et al., 2009).

increase for an $\left(a^{\prime} / d\right)$ of 4 compared to a $40 \%$ increase for an $\left(a^{\prime}\right)$ d) of 3 , given the same amount of transverse reinforcement in the shear span. The same observation was made for specimens without transverse reinforcement in the shear span [an $88 \%$ increase for an $\left(a^{\prime} / d\right)$ of 3 compared to a $138 \%$ increase for an $\left(a^{\prime} / d\right)$ of 4$]$.

Khalifa and $\mathrm{Nanni}^{3}$ also noted that the maximum increase in shear capacity was recorded for the beam that had no transverse reinforcement and had one continuous U-wrapped CFRP ply with fibers oriented to $90^{\circ}$ with respect to the beam axis. The conducted experimental program consistently shows that the externally bonded CFRP has greater effects on specimens without transverse reinforcement than specimens with transverse reinforcement. This finding was later confirmed by a similar study conducted by Pellegrino and Modena. ${ }^{6}$ They tested a total of eleven beams with and without transverse reinforcement. All tested beams had sidebonded CFRP sheets. Pellegrino and Modena ${ }^{6}$ concluded from the results they obtained that the effectiveness of CFRP reinforcement reduces when both steel and CFRP reinforcement are present. The increase in axial rigidity of the CFRP and the ratio between the stiffness of the transverse steel reinforcement and the stiffness of the CFRP sheet lowered the effectiveness of the CFRP. According to this review, it can be predicted that CFRP sheets would be more effective in beams without (or with less) transverse reinforcement than in similar beams with transverse reinforcement.

\subsection{Shear failure mechanism of RC beams strengthened with CFRP}

Pellegrino and Modena ${ }^{6}$ conducted an experimental study to observe and evaluate the failure mechanism of beams strengthened with continuous side-bonded CFRP sheets. The parameter considered in the study was the stiffness ratio between transverse steel shear reinforcement and CFRP shear reinforcement $\left(\rho_{s, f}\right)$. A typical shear-tensile failure pattern was observed for the control beam that had neither transverse nor CFRP shear reinforcement. Pellegrino and Modena ${ }^{6}$ observed that all tested specimens without transverse reinforcement presented a principal crack pattern in a subhorizontal direction near the support and with a direction of approximately $45^{\circ}$ near the point of application of the load. The number of CFRP plies applied did not alter the cracking patterns of the beams. However, one layer of CFRP was enough to radically modify the failure mode of the beam, as was also the case for the beams strengthened with two or three layers. During the experimental program, delamination was the ultimate failure mode observed for RC beams without transverse reinforcement and strengthened with one, two or three layers of side-bonded CFRP.

In the same experimental study, Pellegrino and Modena ${ }^{6}$ also tested specimens with transverse steel reinforcement. Specimens with $\rho_{s, f}$ of 1.37 and strengthened with a single layer of CFRP exhibited failure due to shear cracking with an inclination of about $45^{\circ}$. The specimens showed cracking patterns similar to those of the beam without CFRP except for the increased ductile behavior near failure. Specimens that had transverse steel reinforcement with $\rho_{s, f}$ of 0.46 or 0.68 showed cracks in the bonding zone of the sheet followed by a peeling off of the concrete cover.

In similar experiments conducted by Khalifa and $\mathrm{Nanni}^{3}$ on beams with U-wraps, strips of CFRP or side-bonded CFRP, debonding was the failure mode at ultimate for all specimens that had strips of U-wrapped CFRP plies, whereas specimens strengthened with continuous U-wrapped CFRP failed by concrete splitting. Note that specimens with U-wraps or side bonds did not exhibit fracture or debonding from the concrete surface at ultimate. ${ }^{3}$

However, specimens with double layers of sheets tested by Bimal and Hiroshi ${ }^{5}$ showed rupture along the direction parallel to the CFRP fibers and the sheets did not debond from the concrete. The study also shows that debonding was not generally observed for beams strengthened with both vertically and horizontally aligned fibers. Only one beam strengthened with vertical plies showed debonding after concrete crushing. In specimens with a low sheet depth, final failure occurred in concrete due to one critical crack, whereas the beams with a higher sheet depth failed by concrete splitting and crushing.

Sim et al. ${ }^{8}$ conducted an experiment to observe the shear failure mechanism of RC beams strengthened with Glass Fiber Reinforced Polymer (GFRP), Carbon Fiber Sheet (CFS) and CFRP. They observed that the strengthening material did not affect the shear cracking pattern of the RC beam. All beams failed following the typical diagonal shear cracking patterns (see Figure 2), which were observed in the specimens strengthened with vertical strips. The strengthening materials were torn at an angle perpendicular to the fiber orientation. They observed that specimens strengthened with a $45^{\circ}$ CFRP strip did not have the typical diagonal shear cracking pattern observed in specimens strengthened with $90^{\circ}$ or $0^{\circ}$ fiber orientation, but rather it was found that the specimens strengthened with CFRP strips oriented at $45^{\circ}$ developed shear cracks that progressed vertically to the bottom.

\subsection{Behavior of RC beams shear-strengthened with various FRP types, sheet configurations and layouts}

Retrofit of concrete members with CFRP sheets is an efficient and cost-effective method. However, since the technique has been introduced, engineers have designed various sheet configurations for FRP, all of which have altered the behavior of the RC beam depending on how the FRP was applied. Bimal and Hiroshi ${ }^{5}$ tested eight beams that had different carbon fiber reinforced polymer (CFRP) sheet configurations and depths. All tested beams were designed to fail in shear. The beams used in the experimental program did not have any internal shear reinforcement in the shear span. Bimal and Hiroshi ${ }^{5}$ concluded that the rupture strength of a carbon fiber sheet with vertical fibers is greater than the rupture strength of a carbon fiber sheet with horizontal fibers. The experimental program also shows that the shear capacity of a beam tends not to increase proportionally with additional sheet layers, since the ultimate failure is governed by concrete cracking or splitting and by a loss of aggregate interlock. Following the experimental 


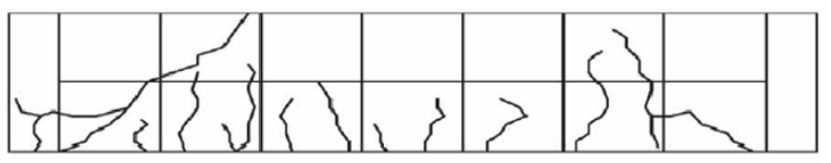

(a) Control $(\mathrm{CON})$

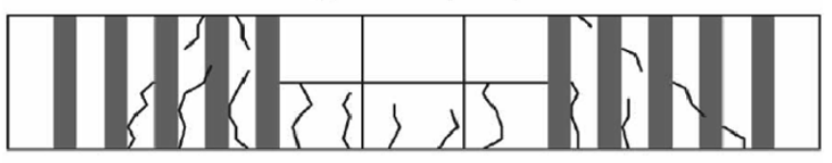

(b) $90^{\circ}$ strip (CP90S)

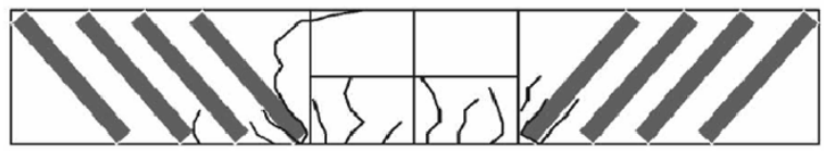

(c) $45^{\circ}$ strip (CP45S)

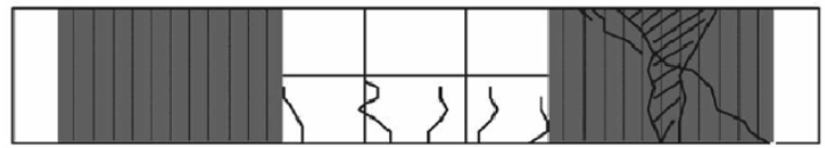

(d) $90^{\circ}$ complete (CS90U)

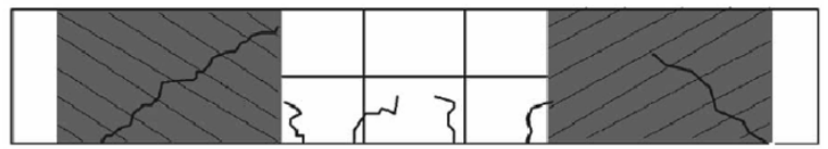

(e) $45^{\circ}$ complete (GP45II)

Fig. 2 Cracking patterns (Adapted from Sim et al., 2005).

program, Bimal and Hiroshi ${ }^{5}$ found that increasing the sheet depth by $50 \%$ resulted in a $108 \%$ increase in shear capacity for specimens that had two CFRP sheets bonded on the sides. A $76 \%$ increase was also noted when the U-wrapped sheet depth was increased by 2 in. (a $50 \%$ increase from the original depth). Specimens strengthened with additional layers of sheet showed only a $3 \%$ increase in ultimate shear strength compared to similar specimens without additional layers of CFRP. The study showed that the extra layer of CFRP did not increase resistance but only allowed additional anchorage to the first layer.

Along the same lines, Khalifa and $\mathrm{Nanni}^{3}$ reported that the increase in shear capacity was not proportional to the increase in CFRP amount. During the experimental study conducted by Khalifa and Nanni, ${ }^{3}$ specimens strengthened with 3 in. wide strips spaced at $5 \mathrm{in}$. exhibited the same failure mechanism and did not yield a significant increase in shear capacity compared to specimens strengthened with 2 in. wide strips spaced at $5 \mathrm{in}$. Note that even a 50\% increase in the CFRP strip width did not generate a noticeable increase in the shear capacity of the beams.

Sim et al. ${ }^{8}$ observed the behavior of RC beams shear-strengthened with GFRP, CFS and CFRP and came to the conclusion that interestingly the different strengthening material did not exhibit a relationship to the strengthening effect. Sim et al. ${ }^{8}$ also noticed that when beams were strengthened with a $45^{\circ}$ fiber orientation, the strengthening effect was increased by more than $10 \%$ in each specimen compared to specimens with $90^{\circ}$ fiber orientation.

\subsection{Behavior of prestressed concrete beams shear-strengthened with CFRP}

Prestressed concrete (PC) is a widely used technique in construction, especially for bridge girders. For such structural mem- bers, repair is often needed when the bridge is sustaining cyclicly overloaded traffic. Researchers have started to shift their focus from repairing $\mathrm{RC}$ members to repairing $\mathrm{PC}$ members using external CFRP; however, there is a lack of research on shear-strengthening of the PC members with CFRP.

Reed and Peterman ${ }^{9}$ conducted both flexural and shear tests on three full scale bridge girders that were replaced by the Kansas Department of Transportation. The three damaged girders were saw-cut in half longitudinally so that six single tee specimens were tested. Since an immediate bond-slip can be caused by an extended web shear crack into the transfer length, ${ }^{10}$ Reed and Peterman ${ }^{9}$ used two distinct setups for the shear test. They tested two girders with no overhang $(\mathrm{NOH})$ and three girders with overhang $(\mathrm{OH})$. This test setup provided an understanding of the influence of CFRP on the propagation of web shear cracks into the transfer length of the prestressing steel. ${ }^{9}$ The shear capacity results for the tested specimens showed that the NOH specimens failed by a bond-slip that was induced by shear crack propagating into the transfer zone of the prestressing reinforcement. On the other hand, the $\mathrm{OH}$ specimens showed a higher shear capacity than the $\mathrm{NOH}$ specimens. The increase was likely due to the longitudinal CFRP wrap holding the web shear cracks closed and increasing the shear contribution due to aggregate interlock.

Another study conducted by Murphy et al. ${ }^{11}$ showed that the failure mode of PC girders strengthened in shear with externally bonded FRP was affected by the stiffness of top and bottom flanges and debonding of the FRP.

\section{Assessment of previous experimental data and analytical models for CFRP shear contribution}

In this section, an interpretation of the available test data and a discussion of the current analytical approaches is presented. An interpretation of the available test data helps identify the parameters that have a certain impact on the shear contribution of CFRP.

\subsection{Experimental data on key parameters influencing CFRP shear-strengthening}

Since the introduction of CFRP shear-strengthening techniques two or three decades ago, researchers have been compiling experimental data in order to better predict the shear contribution of CFRP. Traintafillou and Antonopoulos, ${ }^{16}$ Bousselham and Chaal$\mathrm{lal}^{12}$ and Sas et al. ${ }^{13}$ have compiled a comprehensive list of experimental data from over 30 different studies conducted on RC beams, and the list was reorganized by Ibrahim Ary. ${ }^{14}$ The list has more than 150 beams strengthened with CFRP, Aramid FRP and GFRP. This section particularly investigates the parameters relevant only to beams strengthened with CFRP, and reexamines the compiled data in a different context. Note that this database comprehends a significant update from the one Bousselham and Chaallal $^{12}$ assembled. The investigated parameters include the compressive strength of concrete, the internal transverse steel shear reinforcement, the longitudinal steel reinforcement, the shear span-to-depth ratio and the relationship between the applied CFRP configuration and the mode of failure. The data used for interpretation include T-shaped beams and rectangular beams. The increase in shear due to CFRP contribution is defined as follows: 


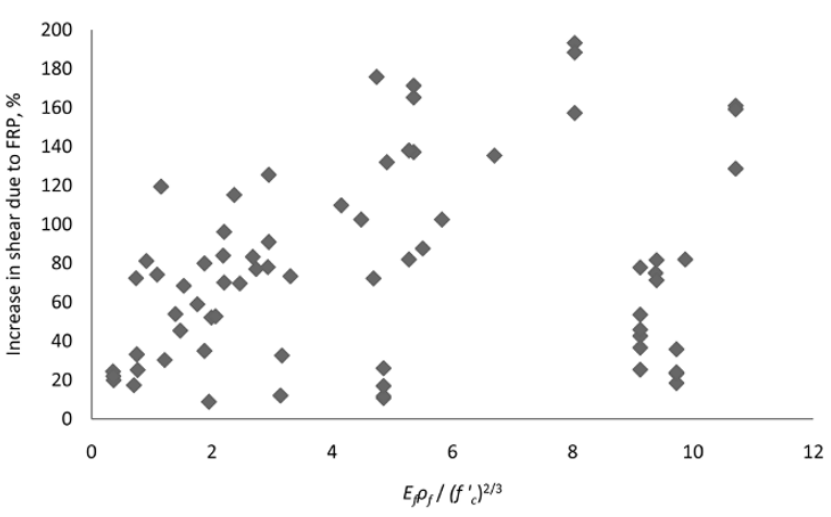

Fig. 3 Interaction between the compressive strength of concrete and increase in shear due to CFRP.

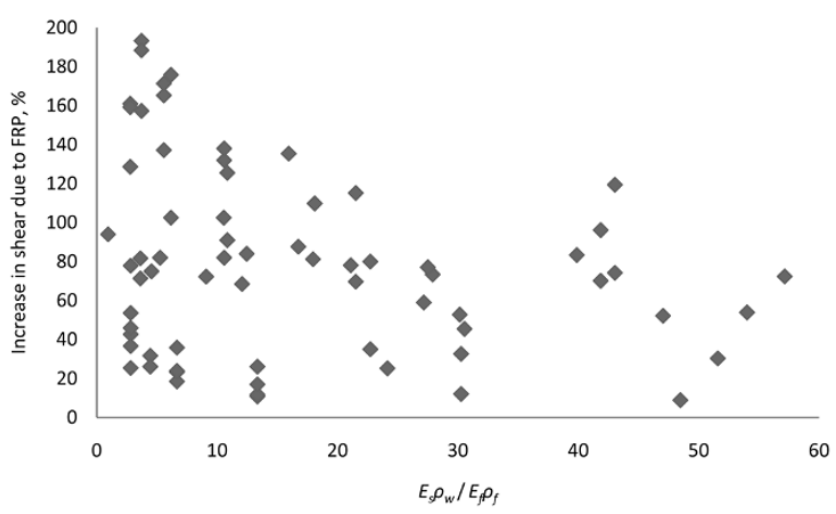

Fig. 4 Interaction between internal transverse shear reinforcement and increase in shear due to CFRP.

Increase in shear capacity due to $\operatorname{CFRP}(\%)=\frac{V_{f}}{\left(V_{t}-V_{f}\right)} \times 100$

where $V_{f}$ is the difference in shear capacity between the control specimen and the strengthened specimen and $V_{t}$ is the total shear capacity of the beam. That increase was used as a basis for measuring the influence of the aforementioned parameters.

Figure 3 shows the interaction between the compressive strength of concrete and the increase in shear due to CFRP. To quantify the effect of the compressive strength against the CFRP, the ratio of $\left(E_{f} \rho_{f} / f_{c}^{, 2 / 3}\right)$ was used, where $E_{f}$ is the modulus of elasticity of the CFRP, $\rho_{f}$ is the CFRP ratio and $f_{c}^{\prime}$ is the compressive strength of the concrete. The general trend resulting from this graph is that the increase in shear due to CFRP appears to become more important as the ratio of $\left(E_{f} \rho_{f} / f_{c}{ }_{c}^{2 / 3}\right)$ increases. This means that specimens constructed with a higher compressive strength exhibit a lower increase in shear capacity due to CFRP application. This trend is consistent up to a value of about $\left(E_{f} \rho_{f} / f_{c}^{, 2 / 3}=8\right)$.

The interaction between transverse shear reinforcement and CFRP was quantified using the ratio of $\left(E_{s} \rho_{w} / E_{f} \rho_{f}\right)$, where $E_{s}$ is the elastic modulus of steel reinforcement, $\rho_{w}$ is the steel shear reinforcement ratio, $E_{f}$ is the elastic modulus of the CFRP and $\rho_{f}$ is the CFRP shear reinforcement ratio (see Figure 4). The general trend here is that the contribution in shear capacity of the CFRP decreases as the ratio of $\left(E_{s} \rho_{w} / E_{f} \rho_{f}\right)$ increases. This means that the more internal steel reinforcement there is in a specimen, the less effective the increase in shear due to CFRP is. The interpreta-

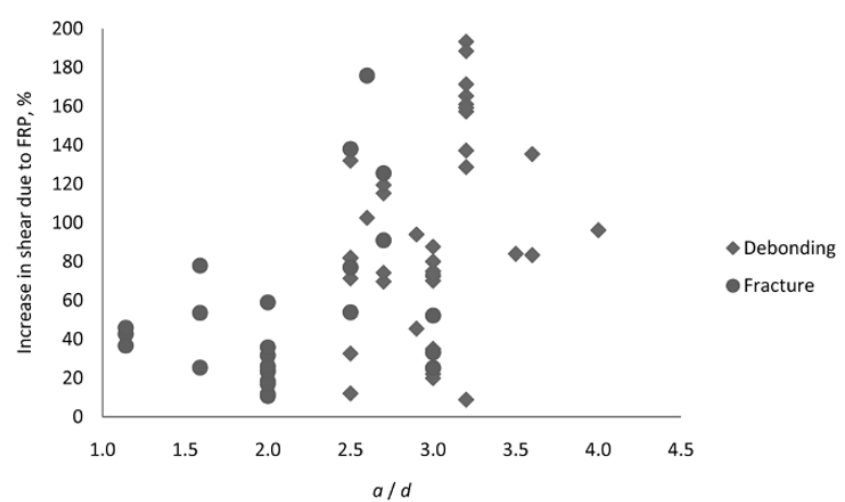

Fig. 5 Interaction between shear span-to-depth ratio and increase in shear due to CFRP and the influence of the failure type.

tion of this graph was also confirmed by Khalifa and Nanni, ${ }^{3}$ who also found that the increase in shear was far more significant in specimens without transverse reinforcement than in specimens with transverse reinforcement.

The shear span-to-depth ratio $\left(a^{\prime} / d\right)$ appears to be an influential parameter, where $a^{\prime}$ is the shear span and $d$ is the effective depth. Figure 5 shows that as the $\left(a^{\prime} / d\right)$ ratio increases, the effective shear contribution of the CFRP also increases. Also, the relation between the type of failure of the specimens and the $\left(a^{\prime} / d\right)$ ratio is notable. It is found from Figure 5 that most of the tested specimens with an $\left(a^{\prime} / d\right)$ less than or equal to 2.5 failed by CFRP fracture while specimens with an $\left(a^{\prime} / d\right)$ greater than or equal to 2.5 failed by FRP debonding. This information indicates that beams with a relatively short shear span tend to experience fracture of the CFRP during loading, whereas for beams with relatively longer shear span, the CFRP sheet is likely to debond from the concrete during loading. Additionally, Khalifa and $\mathrm{Nanni}^{3}$ also found that in some cases the increase in shear doubled for specimens having an $\left(a^{\prime} / d\right)$ of 4 , compared with specimens with an $\left(a^{\prime} / d\right)$ of 3 , regardless of internal shear reinforcement. This raises questions about the effectiveness of CFRP in deep beams since they have a lower $\left(a^{\prime} / d\right)$ (for a constant shear span distance of $\left.a^{\prime}\right)$. Triantafillou ${ }^{15}$ linked the scale effect to the importance of the bond surface area. The deeper the beam is, the more important the CFRP contribution is to the shear resistance; therefore, the amount of CFRP may need to be substantially increased for the deep beams. More research would be needed for shear-strengthening of deep beams using CFRP.

The longitudinal reinforcement, even though used mainly for flexural reinforcement, has a certain influence on the shear performance of CFRP. Figure 6 shows that the largest increase in shear due to CFRP was recorded in specimens with a small amount of longitudinal reinforcement. In specimens with longitudinal reinforcement, the increase in shear due to CFRP appears to be decreasing as the ratio of $\left(E_{s} \rho_{s} / E_{f} \rho_{f}\right)$ increases up to a value of approximately 3 . This means that the contribution of CFRP is reduced in specimens with a relatively large amount of longitudinal reinforcement.

Figure 7 shows the strengthening configuration and the failure mode that resulted from 73 tested specimens. Note that $100 \%$ of the fully wrapped specimens failed in fracture regardless of the shear span-to-depth ratio. Since the specimens were fully 


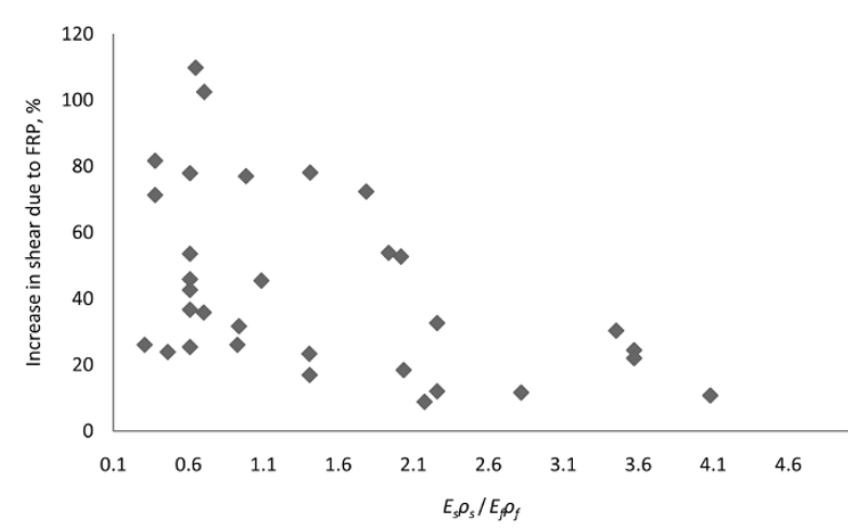

Fig. 6 Interaction between longitudinal mild steel amount and increase in shear due to CFRP.

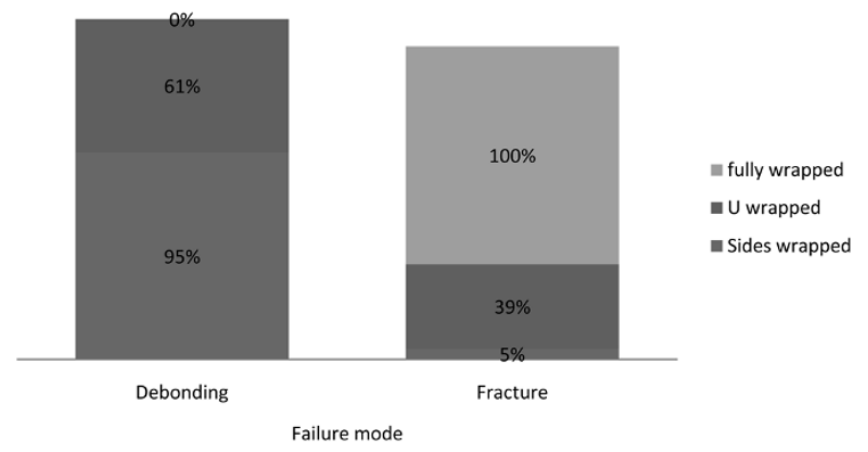

Fig. 7 Interaction between failure mode and CFRP strengthening configuration.

wrapped, debonding of the CFRP was hardly observed. In the Uwrapped specimens (CFRP applied on three sides in a U shape), debonding was observed for $61 \%$ of the tested beams while a little over $1 / 3$ of the total U-wrapped specimens showed fracture of the CFRP at failure. The side-attached specimens failed massively (95\%) with the CFRP debonding from the concrete at failure, and only $5 \%$ of side-attached beams failed with the CFRP being fractured. Figure 7 also shows that debonding of the CFRP is a serious issue especially in side-attached specimens. The debonding appears not to be an issue for the fully wrapped specimens. A clear conclusion could not be drawn for the U-wrapped specimens probably because of the varied shear span-to-depth ratio which plays an important role in the failure mode of the tested specimens.

\subsection{Assessment of existing analytical models estimating FRP shear contribution}

This subsection summarizes two analytical models: 1) the model in the ACI 440.2R- $08^{1}$ recommendations and 2) the model developed by Triantafillou and Antonopoulos. ${ }^{2}$ Both models have been developed to evaluate the shear contribution of externally bonded Fiber Reinforced Polymers (FRP). Assessment of the existing prediction models was based on a database of experimental results assembled by Triantafillou and Antonopoulos, ${ }^{2}$ Bousselham and Chaallal ${ }^{12}$ and Sas et al., ${ }^{13}$ which was reorganized by Ibrahim Ary. ${ }^{14}$ Note that for general model assessment, data for all different kinds of FRP materials were included, not exclusively the CFRP.

\subsubsection{Triantafillou and Antonopoulos model prediction}

Triantafillou and Antonopoulos ${ }^{2}$ defined the total shear contribution of the FRP as:

$$
V_{f}=\frac{0.9}{\gamma_{f r p}} \rho_{f} E_{f} \varepsilon_{f e} b_{w} d(1+\cot \beta) \sin \beta
$$

where $\gamma_{f r p}$ is the partial safety factor for FRP (1.15 for carbon), $b_{w}$ is the web width of the member, $\rho_{f}$ is the FRP area fraction, $\varepsilon_{f e}$ is the effective strain in the FRP, $E_{f}$ is the stiffness of FRP, $\beta$ is the angle of fiber direction to the longitudinal axis of the member and $V_{f}$ is the added shear capacity of the FRP.

This analytical model introduced the effective strain $\left(\varepsilon_{f e}\right)$ of the FRP into the prediction of the added shear capacity of FRP. Additionally, it also considers the type of FRP, the strengthening configuration and the effect of the concrete compressive strength on the effective FRP strain. The effective FRP strain for beams fully wrapped with FRP is defined as:

$$
\varepsilon_{f e}=0.17\left(\frac{f_{c}^{\prime 2 / 3}}{E_{f} \rho_{f}}\right)^{0.3} \varepsilon_{f u}
$$

and the effective FRP strain for beams side-attached or Uwrapped with FRP is defined as:

$$
\varepsilon_{f e}=\min \left[0.65\left(\frac{f_{c}^{\prime 2 / 3}}{E_{f} \rho_{f}}\right)^{0.65} \times 10^{-3}, 0.17\left(\frac{f_{c}^{\prime 2 / 3}}{E_{f} \rho_{f}}\right)^{0.3} \varepsilon_{f u}\right]
$$

Figure 8 shows a comparison of the values derived from the model developed by Triantafillou and Antonopoulos ${ }^{2}$ and the experimental values obtained, also comparing the different FRP configurations (i.e., side-attached, U-wrapped and fully wrapped). The first observation is that this model underestimates the shear contribution of FRP in fully wrapped specimens. For specimens strengthened with side-attached or U-wrapped FRP, Figure 8 shows that for most of the U-wrapped specimens, the model's prediction is close to the experimental values and in most cases overestimates the contribution of FRP to the overall shear capacity of the beam. For side-attached specimens, the model's prediction is not as good as for U-wrapped specimens. Since this model does not consider the bond mechanism between the FRP and concrete, an accurate prediction may not be possible. ${ }^{16}$

The accuracy of the model developed by Triantafillou and Antonopoulos ${ }^{2}$ in predicting the capacity of strengthened rectangular beams and T-beams is shown in Figure 9. The shear contribution of FRP in T-beams is overestimated by this prediction

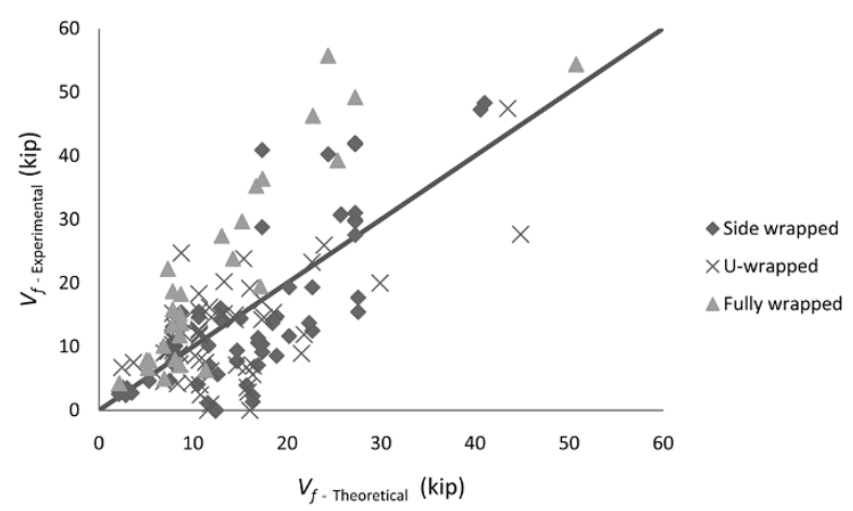

Fig. 8 Triantafillou and Antonopoulos model prediction for various FRP configurations. 


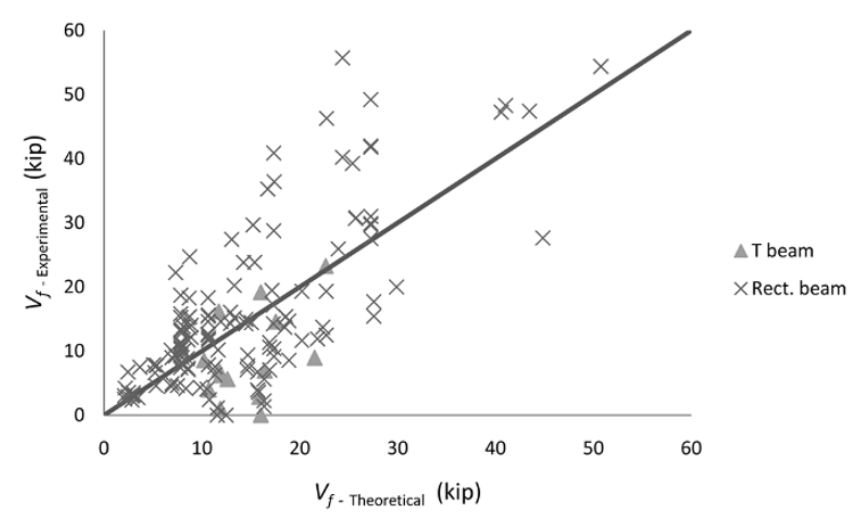

Fig. 9 Triantafillou and Antonopoulos model prediction for various beam section types.

model. The actual contribution of FRP is underestimated by this model only in few cases for T-beams. On the other hand, the model does a relatively decent job estimating the shear contribution of FRP in rectangular beams even though it still overestimates a good chunk of the rectangular beams. Overall, the Triantafillou and Antonopoulos model prediction is a good starting point for estimating the shear capacity of FRP in fully wrapped or Uwrapped rectangular beams.

\subsubsection{ACI 440.2R-08 model prediction}

The ACI 440.2R -08 analytical approach defines the shear contribution of FRP as:

$$
V_{f}=\frac{A_{f} f_{f e}(\sin \beta+\cos \beta) d_{f}}{s_{f}}
$$

where $V_{f}$ is the added shear capacity of the FRP, $d_{f}$ is the effective depth of FRP, $s_{f}$ is the spacing of FRP strips, $f_{f e}$ is the effective tensile stress of FRP and $A_{f}$ is the area of FRP. In contrast to the method developed by Triantafillou and Antonopoulos, ${ }^{2}$ this analytical approach takes into account the bond mechanism that exists between the concrete and the applied external FRP. The contribution of the FRP to the overall shear is based on the fiber orientation and an assumed crack pattern. ${ }^{3}$ This method also uses the effective strain approach but with the exception of limiting the maximum strain that can be achieved by the FRP to $0.4 \%$. This number is mainly based on several test results and experience from industry professionals. The ACI $440^{1}$ analytical approach introduced the bond-reduction coefficient $\left(\kappa_{v}\right)$, which is a function of the concrete strength, the strengthening configuration and the stiffness of the FRP. The bond reduction coefficient $\left(\kappa_{v}\right)$ is defined in ACI 440 as:

$$
\kappa_{v}=\frac{k_{1} k_{2} l_{e}}{468 \varepsilon_{f u}} \leq 0.75
$$

where $l_{e}$ is the active bond length defined as the length over which the majority of the bond stress is maintained, $k_{l}$ is a modification factor that is a function of the concrete strength, $k_{2}$ is a modification factor that is a function of the strengthening configuration and $\varepsilon_{f u}$ is the ultimate strain of the FRP. The effective strain derived from this method is defined as:

$$
\varepsilon_{f e}=\kappa_{v} \varepsilon_{f u} \leq 0.004
$$

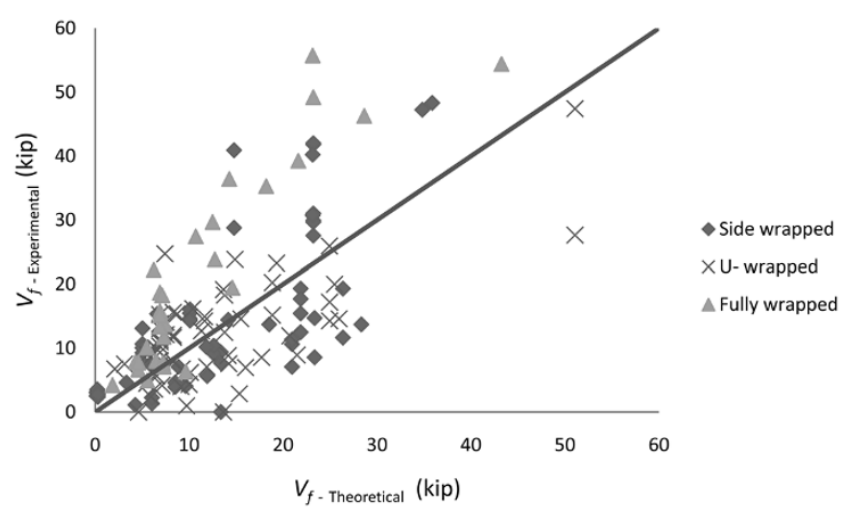

Fig. $10 \mathrm{ACl} 440$ model prediction for various FRP configurations.

Figure 10 shows a comparison between the ACI $440^{1}$ model prediction and the experimental values. The FRP shear contribution was compared for various strengthening configurations and Figure 10 clearly shows that the ACI model underestimates the FRP shear capacity of fully wrapped specimens. In the case of Uwrapped or side-attached specimens, the model presents scattered data around the experimental values, with most of the sideattached specimens being overestimated. This method, in comparison with Triantafillou and Antonopoulos' analytical approach, shows more scattered data around the line.

The ACI $440^{1}$ prediction appears to underestimate the FRP shear contribution in rectangular beams according to Figure 10. Most of the predictions derived from this model for rectangular beams are on the safe side of the line separating experimental values and theoretical values. This can be linked to the fact that the bond reduction factor along with consideration of the active bond length reduces the estimated value. In comparison with Triantafillou and Antonopoulos model, the ACI $440^{1}$ model prediction has a similar accuracy in estimating the FRP shear contribution in rectangular beams (see Figures 8 and 10). For T-beams, the model overestimates the contribution of FRP to the overall shear capacity of the specimen. This model appears to be more suitable for conservative design of fully wrapped rectangular specimens (see Figures 9 and 11).

\section{Conclusions}

The use of Fiber Reinforced Polymers (FRP) for shear-strength-

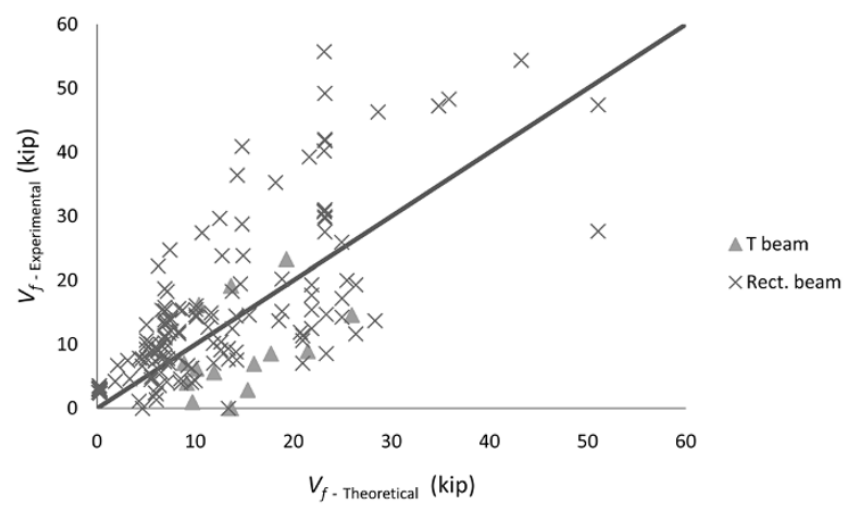

Fig. $11 \mathrm{ACl} 440$ model prediction for various beam section types. 
ening of reinforced and prestressed concrete members is a widely used technique in the industry. In this study, using the compiled extensive prior data, the parameters affecting the shear capacity of externally bonded CFRP were identified and the accuracy of analytical models was evaluated. Based on this research, the following conclusions were drawn.

The increase in shear due to CFRP is higher for a lower concrete compressive strength and/or for a lower amount of longitudinal reinforcement.

The shear capacity of the CFRP decreases (i.e., CFRP is less effective) as the internal steel reinforcement is increased. Conversely, the capacity increases as the shear span-to-depth ratio is increased. Furthermore, the larger the shear span-to-depth ratio is, the more likely debonding will occur.

The comparison with previous experimental data indicates that the accuracy of the model developed by Triantafillou and Antonopoulos ${ }^{2}$ in predicting the capacity of strengthened rectangular beams is relatively good, while the prediction for T-beams and some rectangular beams is not safe.

A similar trend is the case for the ACI $440^{1}$ model, though showing more scatter than the Triantafillou and Antonopoulos model.

Both models can be conservatively used for the fully wrapped FRP, though this application is not common. However, both models are not safe to be applied to the side-attached FRP.

\section{Acknowledgements}

The work presented in this paper was supported by U.S. DOTRITA grant under No. DTRT06-G-0016/OTCREOS10.1-21. The authors would like to thank the second author's undergraduate students, Deanna Quickle and Caroline Weston, for their active participation in the FRP research program at the University of Oklahoma. The views expressed are those of the authors, and do not necessarily represent those of the sponsor.

\section{References}

1. ACI Committee 440, "Guide for the Design and Construction of Externally Bonded FRP Systems for Strengthening Concrete Structures (ACI 440.2R-08)," American Concrete Institute, Farmington Hills, MI, 2008, pp. 76.

2. Triantafillou, T. C., and Antonopoulos, C. P., "Design of Concrete Flexural Members Strengthened in Shear with FRP," ASCE Journal of Composites for Construction, Vol. 4, No. 4, 2000, pp. 198 205.

3. Khalifa, A., and Nanni, A. "Rehabilitation of Rectangular Simply Supported RC Beams with Shear Deficiencies Using CFRP Composites," Construction and Building Materials, Vol. 16, No. 3, 2002, pp. 135 146.

4. Kansara, K. D., Ibell, T. J., Darby, A. P., and Everden, M., "Interpreting Conservativeness in Design Criteria for Flexural Strengthening of RC Structures Using Externally Bonded FRP," International Journal of Concrete Structures and Materials, Vol.
4, No. 1, 2010, pp. 25 36.

5. Bimal, B. A. and Hiroshi, M., "Behavior of Concrete Beams Strengthened in Shear with Carbon-Fiber Sheets," ASCE Journal of Composites for Construction, Vol. 8, No. 3, 2004, pp. 258 264.

6. Pellegrino, C. and Modena, C., "Fiber-Reinforced Polymer Shear Strengthening of Reinforced Concrete Beams With Transverse Steel Reinforcement," Journal of Composites for Construction, Vol. 6, No. 2, 2002, pp. 104 111.

7. Pellegrino, C. and Modena, C., "Fiber-Reinforced Polymer Shear Strengthening of Reinforced Concrete Beams: Experimental Study and analytical Modeling," ACI Structural Journal, Vol. 103, No. 5, 2006, pp. 720 728.

8. Sim, J., Kim, G., Park, C., and Ju, M., "Shear Strengthening Effects with Varying Types of FRP Materials and Strengthening Methods," ACI Special Publication, SP-230, 7th International Symposium on Fiber-Reinforced Polymer (FRP) Reinforcement for Concrete Structures, 2005, pp. 1665 1680.

9. Reed, E. and Peterman, J., "Evaluation of Prestressed Concrete Girders Strengthened with Carbon Fiber Reinforced Polymer Sheets," ASCE Journal of Bridge Engineering, Vol. 9, No. 2, 2004, pp. 185 192.

10. Russell, B., and Burns, N., "Design Guidelines for Transfer, Development, and Debonding of Large Diameter Seven Wire Strands in Pretensioned Concrete Girders," Texas Department of Transportation in Cooperation with Federal Highway Administration, Research Report No. 1210-5F, 1993, pp. 464.

11. Murphy, M., Belarbi, A., and Bae, W., "Shear Strengthening of Prestressed Concrete Girders with Externally Bonded CFRP Sheets," Proceedings of 9th International Symposium on Fiber Reinforced Polymer Reinforcement for Concrete Structures, Sydney, Australia, 2009.

12. Bousselham, A. and Chaallal, O., "Shear Strengthening of Reinforced Concrete Beams with Fiber-Reinforced Polymer: Assessment of Influencing Parameters and Required Research," ACI Structural Journal, Vol. 101, No. 2, 2004, pp. 219 227.

13. Sas, G., Täljsten, B., Barros, J., Lima, J., and Carolin, A., "Are Available Models Reliable for Predicting the FRP Contribution to the Shear Resistance of RC Beams?," ASCE Journal of Composites for Construction, Vol. 13, No. 6, 2009, pp. 514 534.

14. Ibrahim Ary, M., "Shear Strengthening of Prestressed Concrete I-Beams Using Carbon Fiber-Reinforced Polymers," Master's thesis, School of Civil Engineering and Environmental Science, The University of Oklahoma, Norman, 2011, pp. 96.

15. Triantafillou, T. C., "Shear Strengthening of Reinforced Concrete Beams Using Epoxy-Bonded FRP Composites," ACI Structural Journal, Vol. 95, No. 2, 1998, pp. 107 115.

16. Belarbi, A., Bae, W., and Tumialan, R., "Toward Design Guidelines for Shear Strengthening of Concrete Structures Using Externally Bonded FRP Systems," Proceedings of the Advanced Composites in Construction, University of Bath, Bath, United Kingdom, 2007. 